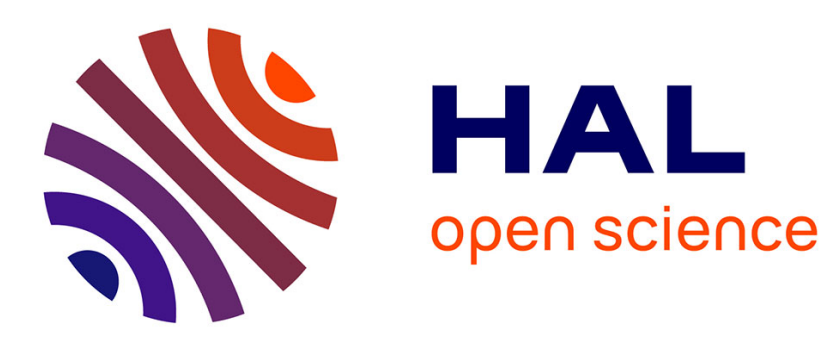

\title{
On the Shoulders of Giants? Motives to Cite in Management Research
}

Matthieu Mandard

\section{To cite this version:}

Matthieu Mandard. On the Shoulders of Giants? Motives to Cite in Management Research. European Management Review, 2022, 19 (1), pp.10-21. 10.1111/emre.12495 . halshs-03439537

\section{HAL Id: halshs-03439537 https://shs.hal.science/halshs-03439537}

Submitted on 12 Feb 2022

HAL is a multi-disciplinary open access archive for the deposit and dissemination of scientific research documents, whether they are published or not. The documents may come from teaching and research institutions in France or abroad, or from public or private research centers.
L'archive ouverte pluridisciplinaire HAL, est destinée au dépôt et à la diffusion de documents scientifiques de niveau recherche, publiés ou non, émanant des établissements d'enseignement et de recherche français ou étrangers, des laboratoires publics ou privés. 


\title{
On the Shoulders of Giants? Motives to Cite in
}

\section{Management Research}

\author{
Matthieu MANDARD \\ Maître de conférences HDR en sciences de gestion / Associate professor in management \\ Université Rennes 1 \\ Centre de Recherche en Économie et Management (CREM - UMR CNRS 6211) \\ 11 rue Jean Macé - CS 70803 - 35708 RENNES Cedex 7 - FRANCE \\ matthieu.mandard@univ-rennes1.fr
}

While citations have been established as a scientific norm used to support assertions and to acknowledge the contribution of past authors, research has widely shown that they are often employed for other motives, such as influencing reviewers, increasing citation rates, showing erudition, etc. Despite the literature that has accumulated on this topic, a general framework inventorying these motives is still lacking. The objective of this methodological paper is thus to offer such a framework. We propose a typology that classifies these motives into four categories: epistemic, rhetoric, symbolic and economic. Through examples drawn from management research, we then present each of the associated citation practices by distinguishing between their nature and their consequences. We finally inventory the subsequent implications of this analysis, both for scientific production and for the evaluation of this production.

Keywords: citation; epistemology; management research; methodology; scientific influence 


\section{Introduction}

Citation, defined as the reference to previous works, is one of the norms of scientific writing (Merton, 1957). Its use has been established in order to support the assertions that are made and to offer some guarantees about their validity. It has also been institutionalized in order to acknowledge the contribution of past authors, these authors being, according to the famous metaphor, giants on whose shoulders the producers of new knowledge are standing (Merton, 1965).

Since the 1960s, however, research on citing behaviour has largely shown that citations are often employed for other motives (Garfield, 1965; Kaplan, 1965). Evidence indicates that, beyond their traditional epistemic role, citations may be adopted in order to influence reviewers, to increase citation rates, to show erudition, etc. (Bornmann and Daniel, 2008; Erikson and Erlandson, 2014). Management studies have long integrated these concerns and have shown that these various uses also exist in our discipline (Harzing, 2002; GoldenBiddle et al., 2006).

Despite the literature that has accumulated on this topic in management research as well as in other academic disciplines, there is still currently no consensus regarding why scholars cite previous works. Papers examining this topic usually offer various lists of motives to cite, ranging from four to more than ten motives (for a review of recent classifications schemes, see Tahamtan and Bornmann, 2019). The problem is that the emphasis has been mainly put on the enumeration of motives rather than on the elaboration of a comprehensive framework that may precisely account for them (Tahamtan and Bornmann, 2019). As Aksnes et al. recently stated, "in spite of detailed studies of referencing behavior, there is no unified theory" $(2019$, p. 6$)$, though there have been recurring calls for such a theory of citation since the 1970s (Nicolaisen, 2007). Consequently, citation practices remain 
unclear, which is problematic as citations lie at the heart of scientific production and evaluation (Gingras, 2016).

The objective of this methodological paper is thus to offer a general framework that inventories the various motives to cite. More specifically, we first propose a typology that distinguishes and articulates four citation motives - namely, an epistemic, a rhetoric, a symbolic, and an economic motive. Second, through examples drawn from management research, we then present each of the associated citation practices by distinguishing between their nature and their consequences. In doing so, we aim to offer a more comprehensive and precisely organized account of this topic than those proposed in previous papers, which may be useful both for scientific production and for the evaluation of this production.

The paper is organized as follows. After a brief historical overview of citation as a norm in scientific writing, we present the typology that we have built in order to classify the various motives to cite. We then detail each of the associated citation practices. We finally discuss the subsequent implications of this analysis for academic research.

\section{Citation as a norm in scientific writing}

The attribution of an intellectual work to its author is a concern that can be traced back to antiquity. In ancient Rome, crediting past authors was considered a way to show them respect and to honour them (Long, 2001). In ancient Greece, writings from Aristotle show that he frequently made references to previous works, whether his own or those from other philosophers such as Plato, Homer, or Empedocles (Small, 2010). We can also find traces of this practice in the Middle Ages, a period during which the metaphor "Standing on the shoulders of giants" was forged by Bernard de Chartres (12 ${ }^{\text {th }}$ century) in order to highlight the importance of referring to past authors in order to develop new knowledge (Merton, 1965). 
During these two periods, however, authors were often cited without precise reference to their work, as they were supposed to be known by readers (Small, 2010). It should also be noted that the use of citations was not widespread and was not a commonly accepted standard (Nicolaisen, 2007).

It is not until the $16^{\text {th }}$ century, and mostly the $17^{\text {th }}$ century, that citations are progressively institutionalized (Nicolaisen, 2007; Small, 2010). It is indeed from this period that a scientific ethos progressively develops, characterized by the creation of scientific societies and journals. The priority in scientific discovery begins to be a matter of concern, and it becomes necessary to correctly attribute findings to their authors (Merton, 1957). With the growth of scientific communities during the $19^{\text {th }}$ century, citation practices are more and more formalized (Allen et al., 1994). The objective is to avoid confusions that could be associated with the multiplication of authors and publications.

This norm rapidly becomes a subject of study, with a first stream of research adopting citations as an indicator of scientific influence (Bornmann and Daniel, 2008). As early as 1927, a first study thus employed citation counts in order to evaluate the impact of the research that was conducted (Gross and Gross, 1927). Because such counts represent accessible data, this idea is then largely adopted and gives rise to numerous investigations aiming at identifying epistemic trajectories on the basis of citations.

In the 1960s, however, a second stream of research begins to question this approach (Garfield, 1965; Kaplan, 1965). Evidence shows that the use of citations is not always motivated by epistemic concerns, and that they may be instrumentalized for other motives. What are the different motives to cite? That is the question that we seek to address in the following sections of this paper. 


\section{Motives to cite in management research: A typology}

Our inventory of the motives to cite is based on a typology that we have constructed. First, we present the methods we have adopted to build it, then the typology itself.

\section{Methods}

To survey a given topic, the most common approach is the systematic review. It aims to 1) collect all the papers that have been published on the topic - preferably in top-tier journals -, 2) identify the core concepts that are employed in these papers - often by coding -, and 3) interpret the key dimensions that emerge from this analysis (Alvesson and Sandberg, 2020). While such systematic reviews have already been conducted on citation motives (Bornmann and Daniel, 2008; Tahamtan and Bornmann, 2019), they have not been fruitful as a general framework that inventories these motives is still lacking (Aksnes et al., 2019).

As a consequence, we have adopted another approach, called the problematizing review - which is in the vein of the traditional narrative reviews. Theorized by Alvesson and Sandberg, its objective is to "re-evaluate existing understandings of phenomena, with a particular view to challenging and reimagining our current ways of thinking about them" (Alvesson and Sandberg, 2020, p. 1297). To do so, as Alvesson and Sandberg indicate: "Rather than undertaking a surface reading of a large volume of available studies, a deep reading of the foundational texts, and of a moderate number of representative texts of a field, enables the author to better identify, articulate and challenge problematic, taken-for-granted assumptions in a specific domain (...). The idea is, then, to read sufficiently to come up with potentially new insights for novel theorizing." (2020, pp. 1299-1300).

Following this reasoning, we thus started by reading a few papers that offered synthesis of the literature on citation motives. While we primarily considered papers 
published in management journals (e.g., Harzing, 2002; Golden-Biddle et al., 2006; Judge et al., 2007; Macdonald and Kam, 2010), in accordance with Alvesson and Sandberg (2020), we also integrated papers from other disciplines that particularly focused on this topic in order to put the review domain into perspective (e.g., Garfield, 1965; Bornmann and Daniel, 2008; Erikson and Erlandson, 2014; Tahamtan and Bornmann, 2019). We then tried to identify the key motives that were evoked in these papers and to build a typology accordingly. We finally extended our review up to about 200 documents $^{1}$ in order to challenge our typology, which appeared to correctly reflect the motives that were mentioned in the literature ${ }^{2}$.

\section{Presentation of the typology}

Our typology highlights four main motives to cite in management research, namely, an epistemic, a symbolic, a rhetoric and an economic motive (Table 1). This typology is organized around two key dimensions.

Please insert Table 1 about here

The first dimension relates to the type of motive that is at stake. Epistemic and rhetoric motives to cite are primarily scientific motives, as they aim to provide scientific grounds for assertions or to convince readers that these assertions are scientifically sound. In contrast, symbolic and economic motives are primarily extra-scientific motives, as they respectively intend to convey a representation of oneself or to get various rewards.

1 References are available upon request.

2 Of course, this methodology is not without limitations, in particular because it strongly relies on researchers' interpretation of the data (Alvesson and Sandberg, 2020). But we think that it is useful, as it allows to renew our understanding of existing areas of investigation and thus to avoid boxed-in research, which is an endemic problem in management studies (Alvesson and Sandberg, 2014). 
The second dimension distinguishes between the way citations are employed. On the one hand, when employed for an epistemic or a symbolic motive, citations are used in order to acknowledge an intellectual influence, whether to support assertions or to convey a particular image of oneself. On the other hand, when employed for a rhetoric or an economic motive, citations are means to exert an influence, as they are intended to convince readers or to obtain rewards.

To be clear, we do not contend that the four motives that we elicit are entirely new, as they have already been identified more or less explicitly in previous work - in particular, the rhetoric use of citations has already been coined by Gilbert (1977) or Cozzens (1989). Likewise, the distinction between scientific and non-scientific motives to cite has already been made by Bornmann and Daniel (2008). Rather, what we claim to be new here is 1) the idea that these four motives are sufficient to encompass every citation practice and 2) the idea that these motives can be classified and thus precisely organized in the typology that we propose $^{3}$.

\section{Motives to cite in management research: A presentation}

Here we present the various motives to cite in management research, by distinguishing between the nature and the consequences of the associated citation practices - which we synthesize in Table 2. It should be noted that, although they are analytically distinct, these motives are not mutually exclusive, as many of them may be present when a reference is made.

3 As Tahamtan and Bornmann wrote: "Rather than classifying citations into many functional categories (every study introduces a new classification system), using some general but exclusive functions would lead to comparable and (perhaps) more reliable results" $(2019$, p. 1675): this is exactly what we aim to offer in this paper. 


\section{Epistemic motive}

Citations following an epistemic motive is the traditional motive to cite, institutionalized in the $19^{\text {th }}$ century (Allen et al., 1994). This use of citations aims to indicate the contribution of past authors in order to support scientific assertions (Merton, 1957).

Nature of the citations. There are different kinds of citations according to this motive (Garfield, 1965; Erikson and Erlandson, 2014; Tahamtan and Bornmann, 2019). References to previous works can be made in a positive way, in order to defend an assertion theoretically, methodologically or empirically. References to previous works can also be made negatively, in order to criticize prior publications or to indicate shortcomings in these publications. Additionally, references can also support an argument only partially, as it is not always possible to find perfect support for a given assertion. For instance, when analysing six articles randomly selected from top management journals and published between 2000 and 2003, Partington and Jenkins found that all of these kind of citations practices - whether positive or negative, and complete or partial - were present in those publications (2007).

Of course, references do not always back up an argument in an univocal manner (Anderson, 2006). Because the thinking of authors may be complex and ambiguous, their work may be subject to interpretation. As March states in a presentation of the reception of the influential book A Behavioral Theory af the Firm he wrote with Cyert, "in a world of thousands of citations, the authors' interpretations are only a small part of the story. What the 
ideas in A Behavioral Theory of the Firm might be imagined to be was shaped by the articles that sought to use them" $(2007$, p. 540). An exegesis is thus sometimes needed to shed light on the thinking of important authors in order to avoid erroneous understandings of their work and to make appropriate uses of it. Over time, commonly accepted interpretations may emerge, making the use of a reference easier (Anderson and Sun, 2010).

Consequences of the citations. In the middle of the $20^{\text {th }}$ century, citation measure led to the emergence of a new discipline intended to quantify scientific literature, labelled scientometrics (Mingers and Leydesdorff, 2015). Its development was in particular the consequence of the creation of a database for inventorying citations, the Science Citation Index, by Garfield in the 1950s (Garfield, 1955). While originally developed as a tool aiming to determine which journal to include in libraries, this index progressively became a device for quantitative evaluations of scientific production and paved the way for the subsequent creation of several other databases (Mingers and Leydesdorff, 2015) ${ }^{4}$.

On the one hand, citations allow to identify the contribution of papers, scholars or journals (Mingers and Leydesdorff, 2015) ${ }^{5}$. For instance, the study of articles published in business and management education research between 1970 and 2014 shows that Ghoshal's article entitled Bad Management Theories are Destroying Good Management Practices (2005) was the most influential paper published on this topic during this period (Arbaugh and Hwang, 2015). In a similar manner, the examination of scholarly influence in the field of management between 1981 and 2004 reveals that Kathleen Eisenhardt, Donald Hambrick and Charles O'Reilly were the three most cited researchers during this period (Podsakoff et al.,

4 The presentation of the various metrics that may be employed to quantify scientific research is beyond the scope of this paper. For an overview of this topic, see Mingers and Leydesdorff (2015).

5 The excessive focus on citations in order to evaluate contributions has been largely criticized. We examine this issue in the discussion part. 
2008). In the same vein, the study of citations in and citations from the Strategic Management Journal between 1980 and 2009 shows that this outlet progressively became an influential source of knowledge in this field of research (Nerur et al., 2016).

On the other hand, citations also inform us about the origin and the evolution of research areas over time (Mingers and Leydesdorff, 2015; Zupic and Čater, 2015). Through the analysis of intellectual trajectories, it is possible to distinguish between recent and mature fields of investigation and to highlight the areas that have been little explored and those that have been largely examined. The analysis of citations from three major operations management journals between 1980 and 2006 thus reveals that this field of research has shifted from narrow tactical toward macro strategic topics over time (Pilkington and Meredith, 2009). Intellectual trajectories also allow for the identification of connections and ruptures between research domains. For example, the examination of cross-citations across social science disciplines indicates that, between 1998 and 2008, after being initially multidisciplinary, innovation research progressively became compartmentalized between management and economics (Shafique, 2013).

\section{Rhetoric motive}

Citations can also be employed according to a rhetoric motive, that is, in order to convince readers (Gilbert, 1977; Cozzens, 1989). While citations for an epistemic motive aim to acknowledge the influence of prior publications on one's thinking, citations following a rhetoric motive intend to exert an influence on the judgement readers will bear on one's work.

Nature of the citations. Research on the sociology of science has largely shown that academic productions are shaped by social conventions aimed to define what is an acceptable scientific 
publication, such as clarity, logical rigour or pertinence to current research in the discipline (Chase, 1970). It appears that, as a key aspect of scientific writing, citation practices are also shaped by norms aimed to define what constitutes a credible reference (Gilbert, 1977; Cozzens, 1989). Of course, because academic disciplines may have different standards, there may be important variations in citation practices across fields of research. To employ sound citations, it is thus necessary to identify the expectations of the readers - editors, referees and, more generally, the scientific audience - to whom a text is addressed (Milojević, 2012).

The soundness of a citation can be related to its very content. Here, each part of a given reference - that is, the author, the journal, the text itself, or even the year of publication - can play a rhetoric role. First, it is possible to cite widely acknowledged authors. It is largely known that famous authors receive more citations than others, as their work is perceived as being more valid than the research of unknown scholars - this is the so-called Matthew effect in science (Merton, 1968). In management research in particular, several studies have thus shown that renowned authors tend to get more citations (Hwang et al., $2019)^{6}$. Second, it is possible to cite prestigious, that is, highly ranked journals. Examining factors that caused management articles to be cited in top management journals between 1990 and 2006, Judge et al. (2007) showed that the most important factor driving citations was the prestige of the outlets in which references were published ${ }^{7}$. Conversely, conference papers and books chapters are generally considered to be less convincing references as they are easier to publish (Colquitt, 2013). Third, famous texts may be regularly cited as an accepted reference in order to illustrate a particular point. For instance, an analysis of citations of Walsh and Ungson's article Organizational Memory (Walsh and Ungson, 1991) indicates that this paper

6 Because of gender discriminations, it is also known that men's work is considered as more valuable and frequently receives more citations than women's. Labelled the Matilda effect (Rossiter, 1993), this phenomenon also seems to be observed in management studies (Czarniawska and Sevón, 2018).

7 While initially employed at the individual level, the Matthew effect thus appears to also exist at the journal level (Drivas and Kremmydas, 2020). 
is commonly mentioned to evoke the use of history by organizations (Anderson, 2006).

Finally, when selecting citations, the year of publication may also be of importance. From a general standpoint, evidence shows that new articles tend to be more frequently cited than old ones, as their results are presumed to be more valid (Hwang et al., 2019).

To convince readers, the quantity of citations also matters. Citations can be employed numerously in order to stress the attention that a topic has previously received or to show that an argument is largely supported (Macdonald and Kam, 2010; Schulz and Nicolai, 2015). The abundance of citations is particularly important at the beginning of a paper, as references allow authors to set out the problem and to show the importance of the issue the paper seeks to address (Schulz and Nicolai, 2015). Overall, as a rule of thumb, a former editor of the Journal of Management suggested that 5-6 pages of references should be considered a reasonable quantity in major journals, while conversely the use of more references could cast doubt on their usefulness and alter readers' perception of the manuscript (Feldman, 2004).

Consequences of the citations. The consequences of rhetoric citations are twofold. On the one hand, the ideas that are developed may be considered as more valid and papers tend to have a greater acceptance rate when considered for publication (Macdonald and Kam, 2007). Because of the huge amount of submissions they receive and the impossibility of carefully reviewing them all, some journals editors as well as some reviewers indeed acknowledge that they take citations into account in order to accept or reject papers (Judge et al., 2007; Macdonald, 2015). Besides a better acceptance rate, papers with sound citations also tend to have a more important citation rate as well, as they appear to be more robust (Macdonald and Kam, 2007). 
On the other hand, references may become routinely employed without precisely elaborating on them. For instance, DiMaggio has deplored that the paper he wrote with Powell on institutions has become routinely cited to evoke organizational isomorphism (DiMaggio, 1995). Similarly, March and Simon's Organizations is frequently cited as an example of a classic work without precisely drawing on it (Anderson and Lemken, 2019). References may even be employed erroneously, as Harzing (1995) showed in her examination of the literature related to expatriates, built on the persistent myth of high failure rates because of massive misquotations of foundational articles. Because of these problems, papers are regularly published to denounce inappropriate interpretations of past works and to deliver a more acceptable presentation of them (e.g., Anderson, 2006; Anderson and Sun, 2010; Anderson and Lemken, 2019). Conversely, original citation practices may be discouraged. An analysis of citation practices of the top 20 authors who frequently published in top management journal over the period 1987-2006 showed that these authors mainly cited top journals and top authors, thus avoiding references that may be unfamiliar to referees or references that referees may not consider robust (Macdonald and Kam, 2010).

\section{Symbolic motive}

When employed following a symbolic motive, citations aim to convey an image of one self (Allen, 1997; White, 2001). While rhetoric citations aim to influence the representation of the research that is conducted, citations according to symbolic motives intend to produce a representation of the researcher her/himself.

Nature of the citations. An image can be induced by cited references in several ways. Similarly to rhetoric citations, the author or the journal may serve as a symbol (Allen, 1997). 
For instance, writings of Marx, Foucault, or Habermas have largely influenced the development of critical management studies and are commonly invoked by members of this community (Hassard et al., 2001). In a similar manner, journals such as Organization, Critical Perspectives on Accounting, or Ephemera are privileged outlets for scholars belonging to this community and are regularly cited by them (Adler et al., 2007). References to these authors or to these journals can thus be instrumentalized in order to indicate an affiliation to the critical management studies community (White, 2001).

Besides authors or journals, various other aspects of a reference may also convey meanings and act as symbols. The years of cited publications may indicate whether scholars belong to traditional schools of thinking or to the avant-garde (Erikson and Erlandson, 2014). The language of cited publications may signal scholars' international openness (Breeze, 2015). The discipline from which a reference originates may also communicate scholars' intellectual affinities (Cronin and Shaw, 2002). Finally, while abundant referencing may be employed to convince readers following a rhetoric rationale, it may also be employed to display erudition. The use of numerous citations may indeed be employed to indicate that authors master a vast knowledge area (White, 2004).

Consequences of the citations. As institutional theory has largely shown, displaying an affiliation to a particular community may have opposite effects (DiMaggio and Powell, 1983). By positioning themselves in particular schools of thought, scholars may increase their legitimacy, and the knowledge they produce may be more easily accepted by their epistemic community (Allen, 1997). Generally speaking, the display of symbols is particularly important when actors are not particularly recognized in a given field and thus lack legitimacy - an issue that is salient when actors are young or new to the field (Zott and Huy, 2007). The 
same rationale seems to apply when using symbolic citations: they are more likely employed by scholars who are not firmly established in a given epistemic community and who thus want to demonstrate that they are one of its members (Breeze, 2015). Conversely, it should be noted that, by cultivating their affiliation to a particular scientific community, scholars tend to exclude themselves from other communities and to receive less credit from their members (Breeze, 2015).

Since the early 2000 s, a stream of research pertaining to scientometrics has emerged which aims to examine authors' citation profiles (Cronin and Shaw, 2002). The objective is to get a better understanding of the social dynamics of knowledge production. Citation profiles can be established at the author level, through the elicitation of the so-called citation identity (White, 2001). In management research, citation profiles have generally been established at the level of a research area. Several studies have thus examined the intellectual foundations of research fields such as accounting, finance, or family business (Chrisman et al., 2010), or information systems (Walsh and Kalika, 2018).

\section{Economic motive}

Finally, citations can also be driven by economic motives (Bedeian, 2003; Smith, 2006; Szomszor et al., 2020). As citation counts are nowadays a key indicator of scientific contribution (Macdonald and Kam, 2010; Reinstein et al., 2011), references to prior works may be made in order to get various rewards.

Nature of the citations. Two key citation strategies may be distinguished here. First, one may cite her/his own work - a practice also known as self-citation - in order to get the gains that we will detail in the next section (Szomszor et al., 2020). A study of citations obtained by 
papers published between 1980 and 2010 in top journals such as the Academy of Management Journal, Academy of Management Review, Administrative Science Quarterly, Journal of Applied Psychology, and Strategic Management Journal revealed, on average, a 19\% selfcitations rate in the year following publication (Walsh, 2011) ${ }^{8}$. In the same vein, it is also possible to cite colleagues and to form 'citation cartels', that is, to form networks of scholars who reciprocally cite each other (Smith, 2006; Szomszor et al., 2020).

Second, one may also cite papers written by the editors and the reviewers of the journals in which articles are submitted, as well as papers that have been published in these outlets. A survey addressed to authors of articles published in the Academy of Management Journal and the Academy of Management Review between 1999 and 2001 showed that 20\% of these scholars included references because they expected to be reviewed by their authors (Bedeian, 2003).

Consequences of the citations. Various benefits may derive from economic citations. Selfcitations may be implemented in order to directly increase researchers' own citation rates and to consequently get the various rewards that are commonly associated with high impact factors, such as recruitment, tenure, teaching load, career evolution, or salary (Macdonald and Kam, 2010; Reinstein et al., 2011; Szomszor et al., 2020). They may also be employed to increase the visibility of one's work in order to be subsequently cited and to finally obtain these rewards (Szomszor et al., 2020). The same rationale applies for reciprocal citations: they aim to increase researchers' citation rates and to reap the benefits previously mentioned (Smith, 2006).

8 Generally speaking, a recent study of citations practices in various scientific areas revealed that about $5 \%$ of all citations were self-citations, with high variation in self-referencing behaviours among authors (Kacem et al., 2020). 
In addition, the citation of editors or reviewers of journals where articles are submitted may increase the chances of getting accepted. Apart from the fact that editors and reviewers may be more receptive to citations from papers they have written and to citations from papers that have been published in the journals they work for, which is a rhetoric motive to cite that we have previously presented, they may be more responsive to such citations as they allow them to increase their own impact factors or the impact factors of their journals (Walsh, 2011). When solicited by the editors or reviewers, citations are called coercive citations. They occur when citations are requested while 1) no references are actually lacking, 2) no specific references have been suggested, and 3) the only guidance provided is to add citations from editors' journals or from reviewers' papers (Wilhite and Fong, 2012).

Of course, instrumental citations are not without risks. When detected, instead of increasing their popularity, these practices may actually undermine the reputation of their authors and of the scholars they cite (Nicolaisen, 2007). For instance, a survey conducted a decade ago among researchers in economics, sociology, psychology, and business showed that coercive citations were not uncommon in those disciplines (Wilhite and Fong, 2012). Many journals consequently established ethical codes of practice forbidding this kind of request (Martin, 2013). Likewise, since 2007, Thomson Reuters' Journal Citation Report no longer publishes metrics of journals that display excessive rates of self-citations and reciprocal citations - and some management journals have thus been suspended in recent years (Honig et al., 2018).

\section{Discussion: Implications for management research}

In this section we discuss the implications of the paper for management research, both regarding scientific production and the evaluation of this production. 


\section{Implications for scientific production}

First of all, through this paper, we aim to recall the epistemic vocation of citations and the importance of ensuring that they are both relevant and accurate. To do so, Harzing proposed twelve guidelines for good academic referencing, which are: 1) reproduce the correct reference, 2) refer to the correct publication, 3) do not use 'empty' references, 4) use reliable sources, 5) use generalizable sources for generalized statements, 6) do not misrepresent the content of the reference, 7) make clear which statement references support, 8) check out the original, 9) do not cite out-of-date references, 10) do not be unduly impressed by top journals, 11) do not try to reason away conflicting evidence and 12) actively search for counterevidence (2002, p. 128). While formulated almost 20 years ago, we think, along with colleagues from management studies and from other disciplines (Colquitt, 2013; Smith and Banks, 2017; van de Weert and Stella, 2019), that these guidelines are still relevant and useful ${ }^{9}$.

Second, this paper also allows us to stress the importance of the rhetoric function of citations. In most cases, this aspect is not formally taught but is experienced by scholars over the course of their careers: our paper thus sheds light on a rather informal practice. To be clear, we are not promoting the use of inappropriate references to mislead readers. Rather, we contend that, when selecting a reference among the various documents that may be cited in order to substantiate an assertion, scholars need to integrate a rhetoric dimension in their choice. The scientific competition to be published, read, and ultimately cited is particularly fierce; scholars have to be aware of this concern if they want to thrive in the academic landscape (Judge et al., 2007; Macdonald, 2015; Macdonald and Kam, 2007, 2010).

9 It can be noted that similar sets of guidelines have been proposed by Campion (1997) and Penders (2018). 
Finally, in this paper, we also shed light on the symbolic dimension of citations. Even if they are not always perceived as such, references are symbols authors may use if they want to be perceived as members of a given academic community (Breeze, 2015; Erikson and Erlandson, 2014). Scholars - and in particular young scholars - should also integrate this concern in their writing strategies.

\section{Implications for scientific evaluation}

With respect to implications for scientific evaluation, we will distinguish between implications regarding the evaluation of submitted papers and those regarding the evaluation of published papers.

Regarding the evaluation of submitted papers. First, it is important to remain vigilant regarding the epistemic function of citations when evaluating papers, and to make sure that the references that are mentioned are accurate. Proper citation is currently an important concern for management journals - and in particular for the European Management Review (Lee et al., 2019). The objective is to avoid referencing errors or malpractices that may both mislead subsequent research and undermine the credibility of our academic community (Harzing, 2002). Studies examining the accuracy of references across disciplines consistently reveal significant error rates, so it seems that we may have room for improvement here (Rivkin, 2020; Serenko et al., 2021).

Second, it is also important to avoid to be too vulnerable to rhetoric citations, as they tend to induce standardised papers. In fact, we think that it is crucial to allow - and even to encourage - the citation of original works in order to enable the emergence of new knowledge. Management studies have been largely criticized for being pervaded by boxed-in 
research, and the openness to original citation practices appears to be a way to induce more box-breaking research (Alvesson and Sandberg, 2014). It is no surprise, therefore, that such an openness to theoretical diversity is nowadays advocated by most management journals: for instance, this is an explicit requirement in the reviewer guidelines of the Academy of Management conference, which states that evaluations have "to be open-minded to different authors using different theoretical frameworks" and should "judge manuscripts based on how well they stimulate thinking and discussion" $"$

Third, it is necessary to remain impermeable to economic aspects and to refuse citations that are intended to obtain counterparts such as a positive evaluation of a paper or a positive appreciation of its authors ${ }^{11}$. Similarly to erroneous citations, this kind of citation practice may undermine the reputation of our research community and is increasingly denounced in academic publishing (Martin, 2013; Hopp and Hoover, 2017; Seeber et al., 2019).

Regarding the evaluation of published papers. Since the 1920s, citation counts have progressively become a key indicator of scientific influence (Gross and Gross, 1927; Gingras, 2016). Management studies are no exception, as they largely rely on them to identify prominent scholars (Aguinis et al., 2014), top journals (Judge et al., 2007), as well as major research centres (Starbuck, 2005). The problem here is that such an evaluation of published papers is guided by the assumption that citations reflect the epistemic importance of scholars' work. However, given what we know about the uses of citations, this indicator should be employed very cautiously as it may actually measure completely different phenomena such as

10 https://aom.org/events/annual-meeting/reviewing/reviewer-guidelines

11 To be clear, self-citations may of course be justified when authors are the experts of a given topic. What we stress here is that self-citations should be refused when they mainly aim to get rewards. 
the rhetoric value of references or the institutional importance of their authors - an issue Garfield himself was well aware of (Baum, 2011).

In order to avoid biases that may be introduced by purely quantitative analysis of citations, a method called citation context analysis was introduced in the late 1970s (Small, 1980). As its name suggests, this approach involves the examination of passages where citations appear in order to determine the way previous texts are interpreted and influence subsequent works (for a recent introduction, see Anderson and Lemken, 2020). In management studies, this method has been adopted to evaluate the true contribution of Walsh and Ungson's Organizational Memory (Anderson and Sun, 2010), the real impact of March and Simon's Organizations (Anderson and Lemken, 2019), or the influence of Pierre Bourdieu in management and organization studies (Sieweke, 2014).

While citation context analysis is interesting, as it allows a more accurate understanding of the information that is retrieved from a reference, its usefulness remain limited for two reasons (Tahamtan and Bornmann, 2019). On the one hand, the reading of a text does not always reveal the true motives to cite. For instance, the reading of sentences in which citations appear may not always allow to distinguish between rhetoric and symbolic motives or reveal that both of them are present. On the other hand, such a context analysis requires an in-depth knowledge of the research area to which the cited document belongs. Therefore, it may be necessary to go beyond the mere analysis of writings and to ask authors directly why they employed particular references in order to clarify their intentions (Harwood, 2009). Survey and interview-based studies have thus been conducted since the 1990s to elicit reasons to cite (Tahamtan and Bornmann, 2019). They have been employed in areas such as communication studies (Case and Higgins, 2000), computing, and sociology (Harwood, 2009) or to understand the citing behaviour of post-graduate business management students 
(Harwood and Petrić, 2012). We think that it could also be adopted in management research in order to shed light on actual citation practices ${ }^{12}$.

Of course, while these methods may be employed to identify true motives to cite and to ascertain the existence of an epistemic influence, research quality is a multidimensional concept that should not be reduced to such an influence (Aguinis et al., 2014; Aksnes et al., 2019). In the past decade, various transdisciplinary initiatives, such as the Leiden manifesto or the San Francisco Declaration on Research Assessment (DORA), have emerged in order to promote more pluralistic approaches to research evaluation. The objective is to evaluate publications not only on the basis of citation analysis, but also through the qualitative assessments of their scientific content and the examination of their impact on policy and practice. Such an impact is a particularly important concern in management studies, a discipline in which research implications for organizational practices are historically required (for a presentation of the multiple indicators that may be employed to measure scholarly impact in management, see Aguinis et al., 2014).

\section{Limitations and future research}

The main limitations of this paper are twofold. On the one hand, as we adopted a narrative approach to synthesize the literature, it could be interesting to verify if our framework correctly integrates every existing motives to cite. On the other hand, in the same vein, as we focused on English literature, future work might examine the validity of the proposed framework in other languages.

12 The main limitation of surveys and interviews studies is that authors may not remember why they have cited a particular article (Tahamtan and Bornmann, 2019). To overcome this problem, it is suggested to investigate recently published papers as authors are more likely to recall the motives that led them to cite. 
Besides, following our developments, key avenues for subsequent investigations are threefold. First, future research could deepen our understanding of citation practices by examining their various antecedents. For instance, it is largely known that the physical or electronic availability of publications (Wang et al., 2018), the nature of the compensation system (Judge et al., 2007), or the cultural context (Deschacht and Maes, 2017) have an influence on referencing. It could be interesting to take these parameters into account when studying motives to cite and their associated citation practices. Second, substitutions and complementarities between citation practices could also be examined. To what extent do rhetoric citations may substitute for epistemic citations? Are epistemic and symbolic citations complementary? To the best of our knowledge, this issue has been little considered: we think it deserves more attention. Finally, it could also be interesting to envision the networks of actors that are involved in citation practices - whether citing or being cited - and their respective connections in order to highlight groups of interest and their objectives. To this end, the use of the actor-network theory (Latour, 2005) could be a fruitful avenue.

\section{Conclusion}

The idea that citations are employed for epistemic motives is strongly anchored, as evidenced by the presence of the sentence "On the shoulders of giants" on the home page of the popular Google Scholar search engine. Yet, publications on the topic show that this is not always the case and that citations are regularly used for completely different reasons - namely, a rhetoric, a symbolic or an economic motive. Through this methodological article, we hope to contribute to forge a more accurate representation of this subject and to offer a framework that may be useful to management scholars, both for scientific production and for the evaluation of this production. 


\section{References}

Adler, P. S., L. C. Forbes and H. Willmott, 2007, "Critical management studies". Academy of Management Annals, 1: 119-179.

Aguinis, H., D. L. Shapiro, E. P. Antonacopoulou and T. G. Cummings, 2014, "Scholarly impact: A pluralist conceptualization”. Academy of Management Learning \& Education, 13: 623-639.

Aksnes, D. W., L. Langfeldt and P. Wouters, 2019, "Citations, citation indicators, and research quality: An overview of basic concepts and theories". Sage Open, 9:

2158244019829575.

Allen, B., 1997, "Referring to schools of thought: An example of symbolic citations". Social Studies of Science, 27: 937-949.

Allen, B., J. Qin and F. W. Lancaster, 1994, "Persuasive communities: A longitudinal analysis of references in the Philosophical Transactions of the Royal Society, 1665-1990". Social Studies of Science, 24: 279-310.

Alvesson, M. and J. Sandberg, 2014, "Habitat and habitus: Boxed-in versus box-breaking research". Organization Studies, 35: 967-987.

Alvesson, M. and J. Sandberg, 2020, “The problematizing review: A counterpoint to Elsbach and van Knippenberg"s argument for integrative reviews". Journal of Management Studies, 57: 1290-1304.

Anderson, M. H., 2006, "How can we know what we think until we see what we said?: A citation and citation context analysis of Karl Weick"s The Social Psychology of Organizing". Organization Studies, 27: 1675-1692.

Anderson, M. H. and R. K. Lemken, 2019, “An empirical assessment of the influence of March and Simon"s Organizations: The realized contribution and unfulfilled promise of a masterpiece". Journal of Management Studies, 56: 1537-1569.

Anderson, M. H. and R. K. Lemken, 2020, "Citation context analysis as a method for conducting rigorous and impactful literature reviews". Organizational Research Methods, forthcoming.

Anderson, M. H. and P. Y. Sun, 2010, "What have scholars retrieved from Walsh and Ungson (1991)? A citation context study”. Management Learning, 41: 131-145.

Arbaugh, J. B. and A. Hwang, 2015, "What are the 100 most cited articles in business and management education research, and what do they tell us?". Organization Management Journal, 12: 154-175.

Baum, J. A., 2011, "Free-riding on power laws: Questioning the validity of the impact factor as a measure of research quality in organization studies". Organization, 18: 449-466. 
Bedeian, A. G., 2003, "The manuscript review process: The proper roles of authors, referees, and editors". Journal of Management Inquiry, 12: 331-338.

Bornmann, L. and H.-D. Daniel, 2008, "What do citation counts measure? A review of studies on citing behavior". Journal of Documentation, 64: 45-80.

Breeze, R., 2015. "Citing outside the community? An investigation of the language of bibliography in top journals". In A.R. Plo and C. Pérez-Llantada (eds.), English as a scientific and research language. Berlin: Mouton de Gruyter, pp. 37-58.

Campion, M. A., 1997, "Rules for references: Suggested guidelines for choosing literature citations for research articles in applied psychology". Personnel Psychology, 50: 165-167.

Case, D. O. and G. M. Higgins, 2000, "How can we investigate citation behavior? A study of reasons for citing literature in communication". Journal of the American Society for Information Science, 51: 635-645.

Chase, J. M., 1970, "Normative criteria for scientific publication". The American Sociologist, 5: $262-265$.

Chrisman, J. J., F.W. Kellermanns, K. C. Chan and K. Liano, 2010, "Intellectual foundations of current research in family business: An identification and review of 25 influential articles". Family Business Review, 23: 9-26.

Colquitt, J. A., 2013, "Crafting references in AMJ submissions". Academy of Management Journal, 56: 1221-1224.

Cozzens, S., 1989, "What do citations count? The rhetoric-first model". Scientometrics, 15: 437-447.

Cronin, B. and D. Shaw, 2002, "Identity-creators and image-makers: Using citation analysis and thick description to put authors in their place". Scientometrics, 54: 31-49.

Czarniawska, B. and G. Sevón, 2018, "Gendered references in organization studies". Qualitative Research in Organizations and Management: An International Journal, 13: 196200

Deschacht, N. and B. Maes, 2017, "Cross-cultural differences in self-promotion: A study of self-citations in management journals". Journal of Occupational and Organizational Psychology, 90: 77-94.

DiMaggio, P. J., 1995, "Comments on" What theory is not"'. Administrative Science Quarterly, 40: 391-397.

DiMaggio, P. J. and W. W. Powell, 1983, "The iron cage revisited: Institutional isomorphism and collective rationality in organizational fields". American Sociological Review, 48: 147160 . 
Drivas, K. and D. Kremmydas, 2020, “The Matthew effect of a journal"s ranking”. Research Policy, 49: 103951.

Erikson, M. G. and P. Erlandson, 2014, "A taxonomy of motives to cite". Social Studies of Science, 44: 625-637.

Feldman, D. C., 2004, "The devil is in the details: Converting good research into publishable articles". Journal of Management, 30: 1-6.

Garfield, E., 1955, “Citation indexes for science”. Science, 122: 108-111.

Garfield, E., 1965. "Can citation indexing be automated". In M. E. Stevens, V. E. Giuliano and L. B. Heilprin (eds.), Statistical association methods for mechanized documentation, symposium proceedings, Washington, DC: National Bureau of Standards, pp. 189-192.

Ghoshal, S., 2005, "Bad management theories are destroying good management practices". Academy of Management Learning \& Education, 4: 75-91.

Gilbert, N., 1977, "Referencing as persuasion”. Social studies of science, 7: 113-122.

Gingras, Y., 2016. Bibliometrics and research evaluation: Uses and abuses. Cambridge, MA: MIT Press.

Golden-Biddle, K., K. Locke and T. Reay, 2006, "Using knowledge in management studies: An investigation of how we cite prior work". Journal of Management Inquiry, 15: 237-254.

Gross, P. L. and E. M. Gross, 1927, "College libraries and chemical education". Science, 66: 385-389.

Harwood, N., 2009, "An interview-based study of the functions of citations in academic writing across two disciplines". Journal of Pragmatics, 41: 497-518.

Harwood, N. and B. Petrić, 2012, "Performance in the citing behavior of two student writers". Written Communication, 29: 55-103.

Harzing, A.-W., 2002, "Are our referencing errors undermining our scholarship and credibility? The case of expatriate failure rates". Journal of Organizational Behavior, 23: $127-148$.

Harzing, A.-W. K., 1995, "The persistent myth of high expatriate failure rates". International Journal of Human Resource Management, 6: 457-474.

Hassard, J., J. Hogan and M. Rowlinson, 2001, "From labor process theory to critical management studies". Administrative Theory \& Praxis, 23: 339-362.

Honig, B., J. Lampel, J. A. C. Baum, M. A. Glynn, R. Jing, M. Lounsbury, E. Schübler, D. G. Sirmon, A. S. Tsui, J. P. Walsh and A. van Witteloostuijn, 2018, "Reflections on scientific misconduct in management: Unfortunate incidents or a normative crisis?". Academy of Management Perspectives, 32: 412-442. 
Hopp, C. and G. A. Hoover, 2017, "How prevalent is academic misconduct in management research?”. Journal of Business Research, 80: 73-81.

Hwang, A., J. B. Arbaugh, R. F. Bento, C. J. Asarta and C. J. Fornaciari, 2019, "What causes a Business and Management Education article to be cited: Article, author, or journal?". The International Journal of Management Education, 17: 139-150.

Judge, T. A., D. M. Cable, A. E. Colbert and S. L. Rynes, 2007, "What causes a management article to be cited—article, author, or journal?". Academy of Management Journal, 50: 491-506.

Kacem, A., J. W. Flatt and P. Mayr, 2020, "Tracking self-citations in academic publishing". Scientometrics, 123: 1157-1165.

Kaplan, N., 1965, "The norms of citation behavior: Prolegomena to the footnote". American Documentation, 16: 179-184.

Latour, B., 2005. Reassembling the Social: An Introduction to Actor-Network-Theory. Oxford: Oxford University Press.

Lee, B., J. Méric and Y. Altman, 2019, "Plagiarism, replication of published material without citation and the policy of the European Management Review". European Management Review, 16: 495-505.

Long, P. O., 2001. Openness, secrecy, authorship: technical arts and the culture of knowledge from antiquity to the Renaissance. Baltimore: Johns Hopkins University Press.

Macdonald, S., 2015, "Emperor"s new clothes: The reinvention of peer review as myth". Journal of Management Inquiry, 24: 264-279.

Macdonald, S. and J. Kam, 2007, "Ring a ring o"roses: Quality journals and gamesmanship in management studies". Journal of Management Studies, 44: 640-655.

Macdonald, S. and J. Kam, 2010, "Counting footnotes: Citability in management studies". Scandinavian Journal of Management, 26: 189-203.

Mandard, M., 2020, "Pourquoi défendre les revues de gestion françaises ? Une revue des arguments en faveur de nos revues". Revue Francaise de Gestion, 291: p. 9-22.

Mandard, M., 2021, "Les fonctions des connaissances produites par les sciences de gestion". Question(s) de Management, 32: 157-165.

March, J. G., 2007, "Perspective-Scholarship, Scholarly Institutions, and Scholarly Communities”. Organization Science, 18: 537-542.

Martin, B. R., 2013, "Whither research integrity? Plagiarism, self-plagiarism and coercive citation in an age of research assessment". Research Policy, 42: 1005-1014. 
Merton, R. K., 1957, "Priorities in scientific discovery: a chapter in the sociology of science”. American Sociological Review, 22: 635-659.

Merton, R. K., 1965. On the shoulders of giants: A Shandean postscript. New York: Harcourt.

Merton, R. K., 1968, “The Matthew effect in science: The reward and communication systems of science are considered". Science, 159: 56-63.

Milojević, S., 2012, "How are academic age, productivity and collaboration related to citing behavior of researchers?". PloS One, 7: e49176.

Mingers, J. and L. Leydesdorff, 2015, "A review of theory and practice in scientometrics". European Journal of Operational Research, 246: 1-19.

Nerur, S., A. A. Rasheed and A. Pandey, 2016, "Citation footprints on the sands of time: An analysis of idea migrations in strategic management". Strategic Management Journal, 37: 1065-1084.

Nicolaisen, J., 2007, “Citation analysis". Annual Review of Information Science and Technology, 41: 609-641.

Partington, D. and M. Jenkins, 2007, "Deconstructing scholarship: An analysis of research methods citations in the organizational sciences". Organizational Research Methods, 10: 399416.

Penders, B., 2018, “Ten simple rules for responsible referencing”. Plos Computational Biology, 14: e1006036.

Pilkington, A. and J. Meredith, 2009, "The evolution of the intellectual structure of operations management-1980-2006: A citation/co-citation analysis". Journal of Operations Management, 27: 185-202.

Podsakoff, P. M., S. B. MacKenzie, N. P. Podsakoff and D. G. Bachrach, 2008, "Scholarly influence in the field of management: A bibliometric analysis of the determinants of university and author impact in the management literature in the past quarter century". Journal of Management, 34: 641-720.

Reinstein, A., J. R. Hasselback, M. E. Riley and D. H. Sinason, 2011, "Pitfalls of using citation indices for making academic accounting promotion, tenure, teaching load, and merit pay decisions". Issues in Accounting Education, 26: 99-131.

Rivkin, A., 2020, "Manuscript Referencing Errors and Their Impact on Shaping Current Evidence". American Journal of Pharmaceutical Education, 84: 877-880.

Rossiter, M. W., 1993, "The Matthew Matilda effect in science". Social Studies of Science, 23: $325-341$. 
Schulz, A. and A. T. Nicolai, 2015, "The intellectual link between management research and popularization media: A bibliometric analysis of the Harvard Business Review". Academy of Management Learning \& Education, 14: 31-49.

Seeber, M., Cattaneo, M., Meoli, M. and P. Malighetti, 2019, "Self-citations as strategic response to the use of metrics for career decisions". Research Policy, 48: 478-491.

Serenko, A., Dumay, J., Hsiao, P.-C. K. and C. W. Choo, 2021, "Do they practice what they preach? The presence of problematic citations in business ethics research". Journal of Documentation, 77: 1304-1320.

Shafique, M., 2013, "Thinking inside the box? Intellectual structure of the knowledge base of innovation research (1988-2008)". Strategic Management Journal, 34: 62-93.

Sieweke, J., 2014, "Pierre Bourdieu in management and organization studies-A citation context analysis and discussion of contributions". Scandinavian Journal of Management, 30: $532-543$.

Small, H., 1980, "Co-citation context analysis and the structure of paradigms". Journal of Documentation, 36: 183-196.

Small, H., 2010, "Referencing through history: How the analysis of landmark scholarly texts can inform citation theory". Research Evaluation, 19: 185-193.

Smith, H. M. and P. B. Banks, 2017, "How dangerous conservation ideas can develop through citation errors". Australian Zoologist, 38: 408-413.

Smith, R., 2006, "Commentary: The power of the unrelenting impact factor-Is it a force for good or harm?”. International Journal of Epidemiology, 35: 1129-1130.

Starbuck, W. H., 2005, "How much better are the most-prestigious journals? The statistics of academic publication”. Organization Science, 16: 180-200.

Szomszor, M., D. A. Pendlebury and J. Adams, 2020, "How much is too much? The difference between research influence and self-citation excess.". Scientometrics, 123: 11191147.

Tahamtan, I. and L. Bornmann, 2019, "What do citation counts measure? An updated review of studies on citations in scientific documents published between 2006 and 2018". Scientometrics, 121: 1635-1684.

Walsh, I. and M. Kalika, 2018, "Network Dynamics in the French-Speaking and EnglishSpeaking IS Research Communities". Systèmes d"Information Management, 23: 67-145.

Walsh, J. P., 2011, "Presidential address: Embracing the sacred in our secular scholarly world". Academy of Management Review, 36: 215-234.

Walsh, J. P. and G. R. Ungson, 1991, "Organizational memory”. Academy of Management Review, 16: 57-91. 
Wang, B., Bu, Y. and Y. Xu, 2018, "A quantitative exploration on reasons for citing articles from the perspective of cited authors". Scientometrics, 116: 675-687.

van de Weert, M. and L. Stella, 2019, "The dangers of citing papers you did not read or understand". Journal of Molecular Structure, 1186: 102-103.

White, H. D., 2001, “Authors as citers over time". Journal of the American Society for Information Science and Technology, 52: 87-108.

White, H. D., 2004, "Reward, persuasion, and the Sokal Hoax: A study in citation identities". Scientometrics, 60: 93-120.

Wilhite, A. W. and E. A. Fong, 2012, "Coercive citation in academic publishing". Science, 335: $542-543$.

Zott, C. and Q. N. Huy, 2007, "How entrepreneurs use symbolic management to acquire resources". Administrative Science Quarterly, 52: 70-105.

Zupic, I. and T. Čater, 2015, "Bibliometric methods in management and organization". Organizational Research Methods, 18: 429-472. 
Table 1 Motives to cite in management research: A typology ${ }^{13}$

Type of motive

Scientific

Extra-scientific

In order to acknowledge an influence

Epistemic

Symbolic

Way citations

are employed

In order to exert an

influence

Rhetoric

Economic

13 While this typology elicits motives to cite in management research, it seems to be transposable to any other discipline. Also, it should be noted that this typology has been developed by analogy with a typology we elaborated to study other topics (Mandard, 2020; Mandard, 2021). 
Table 2 Motives to cite in management research: A presentation

\section{Motive to cite}

$$
\text { Epistemic }
$$

Definition of the motive to cite

Epistemic citations aim to indicate the contribution of past convince readers authors

Nature of the citations

- Contributions can be indicated in a positive or negative, and in a complete or partial way

- Contributions are often subject to interpretation, as authors' thinking may be complex and ambiguous
- Convincingness can be ind by the properties of citations (author, year, journal, etc.)

- Convincingness can also be induced by the quantity of citations
Symbolic

Economic

Symbolic citations aim to produce a representation of the researcher

- Representations can be induced by the properties of citations (author, year, journal, etc.)

- Representations can also be induced by the quantity of citations

Consequences of $\bullet$ Citations allow to identify the $\bullet$ Citations allow the ideas that the citations importance of contributions (of papers, scholars, journals, etc.)

are developed to be considered as more valid

- Citations also inform us about • Citations may become the origin and the evolution of research areas over time

routinely employed without further considerations for their content

- Citations may confer legitimacy to their authors

- Citations also allow to build citation profiles

Cozzens (1989), Gilbert (1977), Allen (1997), Breeze (2015),

Anderson (2006), Garfield $\begin{array}{ll}\text { (1955), Merton (1957), Mingers Judge et al. (2007), Merton } \\ \text { and Leydesdorff (2015), } & \text { (1968), Milojević (2012) }\end{array}$ papers $^{14}$ Podsakoff et al. (2008)
Cronin and Shaw (2002), White (2001, 2004)
Economic citations aim to provide rewards to the researcher

- Rewards can be obtained through self or reciprocal citations

- Rewards can also be obtained through the citation of one stakeholder's work

- Self and reciprocal citations allow researchers to increase their citation rates and to obtain various rewards (recruitment, tenure, teaching load, etc.)

- Citations of stakeholder's work can also increase articles' acceptance rate

Bedeian (2003), Macdonald and Kam (2010), Nicolaisen (2007), Smith (2006), Szomszor et al. (2020)

$\overline{14}$ Representative papers are either seminal or frequently cited papers. 